\title{
Desdobramentos das onze conclusões da esquistossomose no Vale do Paraíba, Brasil, 1967-1969: comunicação breve
}

\author{
Outcomes of the eleven conclusions of \\ schistosomosis in Vale do Paraíba, Brazil, 1967-1969: \\ brief communication
}

Nelson Rodrigues dos Santos ${ }^{1}$, João José Batista de Campos²

1. Médico. Docente aposentado do Departamento de Medicina Preventiva da Faculdade de Ciências Médicas da Universidade Estadual de Campinas (UNICAMP) - Brasil.

2. Médico. Docente do Departamento de Saúde Coletiva do Centro de Ciências da Saúde. Universidade Estadual de Londrina (UEL) - Brasil. ORCID: https://orcid.org/0000-0001-7992-6276

CONTATO: João José Batista de Campos | Av. Rio de Janeiro 1500 (sala 11), Centro | Londrina | Paraná | CEP: 86010-150 | Email: jocampos@uel.br

COMO CITAR: Santos NR, Campos JJB. Desdobramentos das onze conclusões da esquistossomose no Vale do Paraiba, Brasil, 1967-1969: comunicação breve. R. Saúde Públ. Paraná. 2020 Jul;3(1):154-158.

(c) (i) COPYRIGHT Esta obra é disponibilizada nos termos da Licença Creative Commons - 4. 0

RESUMO Trata-se de um breve relato acerca dos desdobramentos das onze conclusões de uma tese de doutoramento em seis ações sobre a instalação e expansão da esquistossomose mansoni autóctone no Vale do Médio Paraíba, no Estado de São Paulo, Brasil. O trabalho tem importância histórica uma vez que foi apresentado e defendido em 1967, à Cátedra de Doenças Tropicais e Infectuosas da Faculdade de Medicina da Universidade de São Paulo (USP), tendo contribuído para o desenvolvimento de outras pesquisas relacionadas à temática até o ano de 1969 e o controle da endemia naquele local à época. 
PALAVRAS-CHAVE: Esquistossomose. Doenças Endêmicas. Saúde Pública. História da Medicina.

\begin{abstract}
This is a brief report about the developments of the eleven conclusions of a doctoral thesis in six actions on the installation and expansion of indigenous schistosomiasis mansoni in the Paraíba Valley, in the State of São Paulo, Brazil. The work is of historical importance since it was presented and defended in 1967, to the Chair of Tropical and Infectious Diseases of the Faculty of Medicine of the University of São Paulo (USP), having contributed to the development of other research related to the theme until the year of 1969 and the control of the endemic in that place at the time.
\end{abstract}

KEYWORDS: Schitosomiasis. Endemics Diseases. Public Health. History of Medicine.

esquistossomose é uma endemia parasitária típica das Américas, Ásia e África. Chegou ao Brasil com os escravos africanos trazidos pela Colônia Portuguesa. No entanto, existem referências da doença muito antes dessa época. Os ovos do esquistossomo (helminto do gênero Schistosoma que causa essa endemia) foram encontrados em múmias chinesas de mais de dois mil anos. No século XXI, a doença ainda é um problema grave de saúde pública. A Organização Mundial da Saúde (OMS) estima que a esquistossomose acometa 200 milhões de pessoas em 74 países. No Brasil, acredita-se que são cerca de seis milhões de infectados?

Conhecida pelos brasileiros como barriga d'água, xistosa ou doença do caramujo, a esquistossomose mansoni ou mansônica é caracterizada na forma mais grave, a hepatoesplênica, pelo aumento do fígado e do baço. O diagnóstico e o tratamento são relativamente simples, mas a erradicação da doença só é possível com medidas que interrompam o ciclo evolutivo do parasito, como a realização de obras de saneamento básico e a mudança comportamental das pessoas que vivem em áreas endêmicas'.

O Vale do Paraíba é uma extensa região localizada entre as serras do Mar e da Mantiqueira, banhada pelo rio que lhe dá o nome. Esta zona que constitui o vale propriamente dito foi de interesse, particularmente. de várias pesquisas relacionadas à esquistossomose, por se tratar de região endêmica, nas décadas 1960 , 1970 e 1980.

Nesse sentido, esta comunicação breve pauta-se em uma pesquisa histórico-social², com o objetivo de examinar a dimensão de uma comunidade à época. Neste caso, os desdobramentos das conclusões de uma série de estudos, realizados entre os anos de 1967 e 1969, que culminou na tese de doutoramento intitulada 
"Esquistossomose no Vale do Paraíba"3, tendo como enfoque a questão da mobilização da população rural com os poderes municipal e estadual no compartilhamento das medidas de saneamento, essenciais para a prevenção da esquistossomose.

No decorrer da realização desses estudos, os contatos com a população urbana e rural do município de Roseira, localizado no Vale Médio Paraíba, e com autoridades locais, ensejaram um processo paralelo de formulação da estratégia de controle da esquistossomose no município, com base em: a) completar a rede urbana de esgoto e construir estação de tratamento; b) promover mudanças nas condições e hábitos familiares referentes ao local da defecação, com ênfase nos escolares e trabalhadores rurais; c) repetir o inquérito malacológico e coprológico um ano após a efetivação do item anterior; e, d) oferecer às autoridades municipais do Vale do Médio Paraíba e às estaduais, a experiência bem-sucedida em Roseira.

Destarte, tal série de estudos, jamais publicados, resultou em onze conclusões da esquistossomose no Vale do Paraíba, das quais foram extraídos os dados para a análise proposta, sendo organizados e interpretados segundo o objetivo desta pesquisa. Essa etapa consistiu num processo de síntese e de inferências sobre as informações contidas nas onze conclusões, desvelando seu conteúdo manifesto e latente², sendo desdobradas em seis ações junto à comunidade à época, as quais foram relevantes à transformação da realidade local e, por conseguinte, à prevenção da esquistossomose, a saber:

1. Registro da coleta para fins de educação à saúde - Aproveitando os momentos da coleta de caramujos nos 20 criadouros no território municipal, assim como as visitas domiciliares e nos locais de trabalho rural, foram fotografadas todas as situações propiciadoras da transmissão da esquistossomose no cotidiano da população. Esta ação possuía a finalidade de exibição pedagógica de slides aos trabalhadores rurais, ao final da jornada diária de trabalho no galpão de cada fazenda e na Escola primária urbana do $1^{\circ}$ grau. A circulação nas fazendas e distritos rurais foi muito facilitada pela adesão de dedicado técnico de extensão rural e sua viatura.

2. Elaboração de peça teatral - Um grupo de munícipes, observando por meses as atividades semanais de coleta dos caramujos em 20 criadouros distribuídos no município, as visitas domiciliares por técnicos de extensão rural instruídos e as projeções dos slides, assumiu por iniciativa própria a elaboração de pequeno e pedagógico script de peça teatral sobre a transmissão dessa endemia e submeteu à nossa opinião, o que resultou na sua encenação nos galpões das maiores fazendas e nas escolas. Compunha esse grupo um poeta popular boêmio, um operário de pequena fábrica de estatuetas de santos em gesso, uma professora primária e um jovem desempregado de liderança entre os jovens. Os diálogos com os trabalhadores rurais e famílias avançaram ao detalhe do governo contribuir com lajotas circulares vasadas para reforma das fossas secas em cada domicílio rural, e cada família confeccionaria ou reformaria sua "casinha" da fossa.

3. Proposta de rede pública de esgoto - Em audiências articuladas com os secretários estaduais de Saúde e de Obras Públicas, seus assessores técnicos com participação do prefeito municipal de Roseira, em alguns meses foram projetados e até 1969 executados os projetos de rede pública de esgotos e da lagoa de oxidação para tratamento, além do fornecimento de 110 lajotas circulares vasadas para reformas higiênicas nas fossas secas domiciliares das residências dos trabalhadores rurais. As lajotas foram entregues em cada domicílio rural pela viatura do extensionista rural.

4. Atendimento no Posto Estadual de Saúde - Foram empreendidas várias iniciativas perante a Secretaria Estadual de Saúde do Estado de São Paulo para a realização de atendimento clínico semanal 
em pequeno Posto Estadual de Saúde, sob insistentes pedidos dos trabalhadores rurais e suas famílias, com base nos sofrimentos e doenças presentes e não somente futuros; todas atendidas, mas em poucas semanas interrompidas. Houve temor sobre a credibilidade dos esforços pelas mudanças de hábitos.

5. Apoio cultural - Apesar das positivas reações dos trabalhadores rurais e suas famílias quanto aos hábitos no destino das fezes humanas no peridomicílio e nos locais do trabalho rural, permaneciam dúvidas sobre a efetiva e duradoura mudança desses hábitos. Mediante a essas dúvidas ocorreu verdadeira idolatria cultural à população que nutria pelas músicas e enredos sertanejos da dupla de cantadores Tonico e Tinoco, a maior audiência do gênero no País. Por três meses foram mantidos contatos com essa dupla, a fim de relatar as pesquisas e ações de controle da esquistossomose em Roseira e obter sua disposição em oferecer nesse município um show gratuito no único cinema existente, com músicas e letras referentes aos hábitos relacionados aos riscos da contração da esquistossomose e outras verminoses. A Prefeitura Municipal viabilizou o uso do cinema, os ingressos gratuitos destinados com prioridade à população rural, secundada pela população urbana, e o show foi realizado no cinema abarrotado. Quatro meses após, a mesma iniciativa foi reproduzida, agora perante o maior ator e cineasta brasileiro na área da cultura rural, Amácio Mazzaropi, cujo estúdio era em sua fazenda no município de Taubaté, próximo de Roseira. Novamente o cinema foi abarrotado e os traços culturais a favor da erradicação da esquistossomose autóctone em Roseira e no Vale do Médio Paraíba, positiva e profundamente impactados.

6. Iniciativas próprias - Em 1968/1969 o técnico de extensão rural procedeu, por sua iniciativa, checagens dos hábitos e opiniões de trabalhadores rurais, o mesmo ocorrendo com vários munícipes, sempre com resultados positivos.

Por fim, é possível inferir que tais ações apontaram inquérito malacológico e coprológico final, orientador do controle parcial ou total da esquistossomose no município de Roseira, talvez no Vale do Médio Paraíba, bem como incentivaram o desenvolvimento de outras pesquisas relacionadas à temática até o ano de 1969. A explicação científica final da não expansão da esquistossomose no Vale do Médio Paraíba permanece devida, sendo enriquecida a partir da década de 1970 com a explosiva migração campo-cidade vinculada à grande pauperização rural e nas pequenas cidades.

Destaca-se que os desdobramentos das onze conclusões da esquistossomose no Vale do Paraíba, aqui relatados brevemente em seis ações, não foram publicados, em virtude do regime político sob feroz ditadura civil-militar, que culminou ao final de 1969 com buscas policiais para prisão política do autor da tese à época. Recentemente, apoiada pela Fundação de Amparo à Pesquisa do Estado de São Paulo (FAPESP), a tese "Esquistossomose mansoni autóctone no Vale do Médio Paraíba $3^{3 "}$ foi disponibilizada na íntegra na Biblioteca Virtual do Instituto de Estudos em Saúde Coletiva (iNESCO).

\section{REFERÊNCIAS}

1. Katz N. Almeida K. Esquistossomose, xistosa, barriga d'água. Cienc Cult. [Internet]. 2003 Jan [cited 2020 Mar 30];55(1):38-43. Disponivel em: http://cienciaecultura.bvs.br/scielo.php?script=sci_arttext\&pid=S0009-67252003000100024\&lng=en.

2. Barros JD. O campo da história. 9. ed. Rio de Janeiro: Vozes; 2013. Especialidades e abordagens. 
DESDOBRAMENTOS DAS ONZE CONCLUSÕES DA ESQUISTOSSOMOSE NO VALE DO PARAIBA, BRASIL, 1967-1969: COMUNICAÇÃo BREVE

3. Rodrigues NR. Esquistossomose mansoni autóctone no Vale do Médio Paraíba, Estado de São Paulo, Brasil. Contribuição para o estudo de zona endêmica [Tese]. São Paulo: Faculdade de Medicina, Universidade de São Paulo; 1967. Disponivel em: http://www.inesco.org.br/ publicacoes/livros/nelsao/.

RECEBIDO: 30/03/2020

ACEITO: 09/06/2020 